\title{
Danças Brasileiras e Psicoterapia: Um Estudo Sobre Efeitos Terapêuticos ${ }^{1}$
}

\author{
Déborah Maia de Lima² \\ Norberto Abreu e Silva Neto \\ Universidade de Brasília
}

\begin{abstract}
RESUMO - Esta investigação foi um estudo de natureza exploratória e qualitativa sobre efeitos terapêuticos em participantes do Grupo Baiadô: Pesquisa e Prática de Danças Brasileiras da Universidade Federal de Uberlândia. A pesquisa utilizou um questionário englobando: a) compreensão do conceito de Cultura Popular; b) modificações advindas pela permanência no grupo; c) informações pessoais dos participantes; d) efeitos terapêuticos auto-identificados pelos membros. As perguntas abertas foram analisadas por meio de análise de conteúdo. Os resultados indicam a existência de efeitos positivos em decorrência da participação no grupo. Foi também encontrado que, independentemente da atuação em um contexto de danças brasileiras, o vínculo entre seus integrantes tem fundamental relevância nas modificações descritas pelos mesmos.
\end{abstract}

Palavras-chave: dança brasileira; cultura popular; efeito terapêutico.

\section{Brazilian Dance and Psychotherapy: A Study of Therapeutic Effects}

\begin{abstract}
The present exploratory and qualitative study aimed to verify the existence of therapeutic effects related to participation in the Baiadô project of the Federal University of Uberlandia. In the study a questionnaire was used which topics included: a) comprehension of the project members concerning popular culture; b) intrapersonal changes regarded as consequence of participation in the project; c) personal information about the participants; d) individual therapeutic effects self-identified. The open questions were analyzed using the method of content analysis. The results indicated that a substantial part of the project participants recognized the existence of positive effects due to the project participation. It was found that the bond between the members and the relationship among them were of fundamental importance for the described changes.
\end{abstract}

Keywords: Brazilian dance; popular culture; therapeutic effect.

O presente artigo desenvolveu-se a partir da dissertação de mestrado Dança Popular e Psicoterapia: Um Estudo sobre "Efeitos Terapêuticos" em Integrantes do Grupo Baiadô - Pesquisa e Prática de Danças Brasileiras", realizada na Universidade de Brasília. A pesquisa teve por objetivo a elaboração de um pré-teste que possibilitasse a observação dos efeitos terapêuticos proporcionados pela participação em um grupo que utilizasse as danças brasileiras como elemento artístico.

Quando se fala em psicologia, mais especificamente, em psicoterapia, é de senso comum a idéia primeira de se tratar de uma forma de atendimento clínico onde a linguagem falada é o canal pelo qual o psicoterapeuta toma conhecimento dos conflitos e angustias de seu paciente. Ao contrário do que acontece na época da infância, com o decorrer da idade, a criatividade e a

1 Este artigo é um extrato da dissertação de Mestrado, Dança Popular e Psicoterapia: Um Estudo sobre "Efeitos Terapêuticos" em Integrantes do Grupo Baiadô - Pesquisa e Prática de Danças Brasileiras, defendida e aprovada em 18 de agosto de 2002 pelo Programa de Psicologia Clínica e Cultura do Departamento de Psicologia da Universidade de Brasília, sob orientação do Prof. Doutor Norberto Abreu e Silva Neto. A pesquisa recebeu o fomento da Coordenação de Aperfeiçoamento de Pessoal de Nível Superior (Capes) e teve a colaboração do Grupo Baiadô - Pesquisa e Prática em Danças Brasileiras, pertencente à Universidade Federal de Uberlândia. Apoio: CAPES.

2 Endereço para correspondência: Déborah Maia de Lima., Av. Afonso Pena, 112 apt. 602, Uberlândia - MG - 38400-128 - Brasil Endereço eletrônico: deborahclinica@gmail.com imaginação começam a seguir uma forma já pré-concebida e conhecida dentro de um modelo aceito e esperado pela escola, família, sociedade, cultura, e inclusive pela própria ciência.

Excetuando-se as abordagens terapêuticas com enfoques corporais, como, por exemplo, a Bionergética ${ }^{3}$, a Biodança ${ }^{4}$ ou os trabalhos de Wilhelm Reich, ${ }^{5}$ tem-se como principal meio de comunicação, a fala como veículo de contato com o cliente em psicoterapia clínica. A linguagem corporal pode ser mais observada pela sua ausência do que por ser determinante de um olhar psicológico dentro do consultório.

Como recurso psicoterapêutico, alguns elementos artísticos ou estimulantes da criatividade tem sido apontados como possibilidades de intervenção em contextos psiquiátricos ou terapêuticos. (Abreu e Silva, 1977; Castro, 1992; Koch, Morlinghaus \& Fuchs, 2007; Thulin, 1997). Todavia, é difícil de se encontrar, em Psicologia, estudos sobre utilização da cultura popular, principalmente das

3 Bionergética: Linha terapêutica que procura entender a personalidade em termos do corpo e seus processos energéticos. (Lowen \& Lowen, 1985).

4 Biodança é um sistema de integração afetiva, renovação orgânica e reeducação das funções vitais, baseado em vivências geradas pelo movimento e pela dança.

5 Wilhelm Reich (1897-1957), discípulo dissidente de Freud, trabalhou os conflitos de poder nas relações sociais e suas implicações emocionais, desenvolvendo amplas pesquisas sobre os processos vitais de energia. 
danças populares brasileiras, como instrumento na clínica psicoterápica. Pouca tem sido também, a exploração dessa especificidade cultural no campo da saúde, seja como facilitadora de desenvolvimento de criatividade, ou de crescimento pessoal e intelectual do indivíduo.

Acredita-se que o ato de dançar seja tão antigo quanto à capacidade humana de se locomover como um bípede (Bramble \& Lieberman, 2004), entretanto, estima-se que suas origens sejam bem mais antigas (Sachs, 1937; Langer, 2006). Dançar envolve mais do que simplesmente se movimentar. $\mathrm{Na}$ dança, estão inseridas possibilidades múltiplas de contato com o mundo em uma linguagem particular que propicia interação, comunicação, movimentação corporal e de uma atuação física no ambiente.

A dança também traz em sua essência a possibilidade de criação. Uma característica bastante necessária dentro do trabalho psicológico. Se pensarmos que as dificuldades psicológicas em se encontrar saídas para dores e sofrimentos também estão ligadas a uma dificuldade ativação de portas criativas diante de problemas ou situações presentes, o treino criativo deveria ser tomado com maior seriedade pelos profissionais de psicoterapias.

Essa dificuldade de incentivo ao "ser criativo" é vista, também, na formação do profissional de Psicologia. De acordo com Zanella e Titon(2005), foi a partir de 1999, que houve um aumento no número de produção científica a respeito da criatividade nos programas brasileiros de pós-graduação em psicologia. A concentração destes trabalhos se restringe à região sudeste, com $83 \%$ dos estudos. Dos sessenta e oito trabalhos analisados na pesquisa, vinte e dois utilizaram alguma linguagem artística, mas somente em aproximadamente cinco por cento foi utilizada a dança (nos estudos observados, havia uma interface com a biodança). Todas as teses e dissertações encontradas na pesquisa se localizavam em outras áreas da psicologia, exceto na clínica. Uma vez que os estudos universitários brasileiros prestam-se à produção de conhecimento científico, a apropriação e o entendimento de recortes das manifestações culturais oferecem ao pesquisador uma importante extensão de seus conhecimentos, em relação aos fenômenos sociais e culturais, e de como esses fatores podem auxiliar na melhora de quadros clínicos psicológicos.

\section{A dança utilizada como terapia}

Como exemplos de inserções da dança como auxiliar terapêutica pode-se citar a Dança - Movimento Terapia. Trata-se de uma modalidade de trabalho terapêutico, realizada em clínicas, hospitais, centros de correção ou escolas, e utilizada em grupos ou em sessões terapêuticas individuais. Esse estilo de terapia de apoio tem como fonte a idéia de que, as formas com que os movimentos corporais acontecem, revelam informações a respeito de emoções internas e processos mentais. A maneira com que as pessoas dançam, sua coordenação motora, a utilização do espaço, sua forma de caminhar e tensões musculares, é capaz de comunicar conflitos internos (Wolberg, 1988) .

Danças de improvisação, com freqüência, mostram gestos e movimentos de partes especiais do corpo. Características como as hesitações ou a forma agressiva nos movimentos e seqüências de expressões corporais têm um significado para o dançarino. Neste contexto, a dança pode ocasionar, não somente uma forma segura de soltar a emoção, mas também, traz à tona atitudes e conflitos pessoais (Wolberg, 1988; Fux, 1983).

Estilos de dança utilizados na dança - movimento terapia são os solos, as improvisações, as danças folclóricas e também danças de salão, auxiliando em uma externalização de sentimentos. Os ganhos com a experiência propiciados através desta arte é outro aspecto importante de se tomar nota. A possibilidade de se estar em um ambiente social, lidar com características como timidez e acanhamento em direção a outra condição de se expressar têm se traduzido com uma grande propiciadora de assertividade pessoal.

Outras estratégias utilizadas por terapeutas de movimento são as técnicas, grupais ou individuais, de consciência corporal. Algumas, apontadas por Wolberg (1988), são o Yoga, o Tai-Chi-Chuan e o relaxamento progressivo.

Um estudo realizado por Koch, Morlinghaus e Fuchs (2007), investigando os efeitos de intervenção terapêutica utilizando-se a dança - movimento terapia na diminuição de estados depressivos e aumento de vitalidade em pacientes psiquiátricos ${ }^{6}$, mostrou como resultado uma melhora significativa nos quadros depressivos, aliado a um aumento de vitalidade nos sujeitos participantes.

Nos Estados Unidos, esta abordagem tem sido endossada pela comissão presidencial em saúde mental. Existe uma série de programas de Mestrado disponíveis e que capacitam o profissional a utilizarem esta técnica, que também pode ser encontrada na Itália e na Espanha.

Precursora da terapia através da dança na década de 30, Marian Chace exerce um importante papel neste campo. Uma vez que este trabalho terapêutico, por meio da dança, usa o corpo e o movimento como instrumento, ao invés de uma comunicação puramente verbal, existe intrínseco nele, a convicção de que o homem é um todo integrado (Abreu e Silva ,1977).

Outra pioneira na relação entre dança e terapia foi Maria Fux, que participou ativamente do movimento da utilização da dança como instrumento terapêutico e educacional e como um meio de comunicação para pessoas que buscam a conexão entre corpo e mente. Fux cria a chamada Dançaterapia e compartilha da idéia de que a dança pertence a todos, podendo ser utilizada na educação e com fins terapêuticos.

A meta de seu trabalho é a totalidade. Suas sessões iniciam-se com o estímulo no sentimento de confiança do participante, de modo que ele não se sinta observado e isolado. $\mathrm{O}$ início das atividades acontece com a tomada de consciência das pessoas em relação a seus corpos. O aquecimento corporal começa tanto no chão quanto em pé. Gradativamente, os participantes vão sendo encorajados a aumentarem sua liberdade corporal e a buscarem o deslocamento na sala. É neste exercício de deslocamento que se inicia um trabalho de improvisações, onde o corpo se entrega a possibilidades de criação, que gera confiança, e personifica a música e o canto (Fux, 1983).

6 Pesquisa realizada com 31 pacientes do Hospital Psiquiátrico Universitário em Heidelberg, Alemanha. Os sujeitos foram divididos em três grupos, onde um grupo pedalou em uma bicicleta ergométrica, outro participou de um grupo de danças circulares com uma música israelense de ritmo alegre, e um terceiro grupo somente ouvia a música tocada (Koch, Merlinghaus, Fucks, 2007). 
Além de utilizar a voz em suas sessões, a música exerce um papel importante no trabalho de Maria Fux. São utilizadas tanto músicas medievais, gravações do clássico, barroco, músicas folclóricas como músicas contemporâneas transmitidas pela mídia, em rádio e televisão.

Apesar de ser mais comum encontrar pesquisas a respeito do efeito do trabalho com o movimento com pacientes diagnosticados como "doentes mentais", é inegável que a dança é uma grande aliada na busca de saúde a qualquer pessoa que dela queira usufruir, seja com fins terapêuticos ou, simplesmente, como lazer ou com fins educativos.

Trabalhos como os de Castro (1992); Koch e cols, (2007) Peto (2000), Farr (1997), Fux (1983), Chace (conforme citado por Abreu e Silva, 1977), entre outros, direcionam para um terreno promissor entre a relação do trabalho psicológico com a arte da dança. Estas "terapias pela dança" propiciam aumento de auto-estima, de saúde corporal, de vitalidade, de autoconsciência, além de uma ampliação da consciência corporal e de uma apropriação do paciente de seu corpo. Esse é um fator fundamentalmente valioso na busca de uma melhor qualidade de vida.

Nos estudos sobre a relação das danças e terapias, percebeu-se uma maior freqüência de utilização da dançaterapia ou dança - movimento terapia como técnicas de apoio para o trabalho corporal em pacientes. As danças folclóricas foram citadas como passíveis de utilização. Contudo, não foi encontrado um estudo que pudesse esclarecer quais os efeitos terapêuticos estas danças poderiam ter como possíveis contribuições em psicologia.

Dentro da formação sociocultural e religiosa brasileira é evidente a utilização do movimento dançado. Temos as celebrações do carnaval, da folia de reis, das quadrilhas juninas, das festas nordestinas, do culto aos orixás, do candomblé, e de várias outras manifestações, tão presentes na identificação do povo brasileiro. As danças populares são formadas por movimentos que possibilitam a interação tempo/espaço, experiências de consciência das variações de tônus e de equilíbrio físico e mental (eutonia ${ }^{7}$ ), de improvisações, e de contato.

Dentro de uma prática e a observação empírica das danças brasileiras, é possível perceber algumas peculiaridades que instigaram o desenvolvimento deste trabalho: 1) é comum a observação da manifestação de um sentimento de alegria e de bem estar por parte das pessoas que participam destas danças; 2) é comum que estas brincadeiras dançantes aconteçam em ambientes populares, ao invés de locais fechados ou palcos. Este fato propicia uma aproximação com o público, e dá a oportunidade às pessoas que assistem, de "estar junto" e de "fazer parte" do contexto apresentado; 3 ) várias danças populares, como a Ciranda e o Cacuriá, têm como característica o convite à inclusão das pessoas que assistem à apresentação. Isto permite um compartilhamento entre dançadores e platéia, incentivando a participação de todos; 4) ao mesmo tempo em que são coletivas estas danças requerem uma noção de singularidade pessoal. $\mathrm{O}$ uso da criatividade costuma ser bem-vindo

7 Criado por Gerda Alexander, a eutonia tem como objetivo trabalhar a conscientização corporal a fim de proporcionar equilíbrio físico e mental. quando adicionado ao costumeiro passo de uma dança em especial. (é permitido "inventar" a própria forma de fazer o passo e dar um "tempero próprio" ao que se dança); 5) nos grupos de tradição popular, as danças populares brasileiras tendem a se perpetuarem entre seus participantes. Existe uma noção de continuidade, que passa de geração para geração. Essa tradição dá uma noção de raiz, de conhecer quem eram os antepassados dentro daquela história, aproximando indivíduo e grupo.

Uma vez que pesquisas sobre estas relações são ainda bastante escassas na área de atuação das terapias, um estudo sobre um grupo que pratica e estuda as danças brasileiras foi realizado. Integrantes do Grupo Baiadô: Pesquisa e Prática das Danças Brasileiras aceitaram o convite para participar de uma pesquisa que pudesse investigar "como" e "quais" efeitos a participação em um grupo que utiliza práticas das danças brasileiras pode causar em seus integrantes. O objetivo principal desta investigação foi ampliar conhecimentos a respeito de quais efeitos terapêuticos estas danças poderiam propiciar em pessoas fora das comunidades tradicionais, favorecendo sua utilização como instrumento na busca de um bem estar mental, emocional e corporal nas pessoas que delas se apropriem.

\section{Método}

\section{Participantes}

Fizeram parte da coleta de dados deste estudo, participantes do Grupo Baiadô: Pesquisa e Prática das Danças Brasileiras, grupo fundado em 2002, pela professora Renata Bittencourt Meira. Trata-se de um grupo de pesquisa, ensino e extensão vinculado ao laboratório de ações corporais, e aprovado pelo departamento de música e artes cênicas da Universidade Federal de Uberlândia (UFU). O grupo utiliza a infra-estrutura da universidade para a execução de suas atividades. A transmissão de noções sobre a utilização da dinâmica espaço-tempo na cultura popular, a relação entre canto, dança, instrumentos musicais, adereços, figurinos, a formação e capacitação de seus integrantes para o ensino de oficinas de danças brasileiras, são preocupações que acompanharam o grupo desde seu início. Como projeto de extensão, o Baiadô é aberto à comunidade $\mathrm{e}$ isento de mensalidades. $\mathrm{O}$ grupo aceita pessoas interessadas em cantar, dançar, tocar, versar e aprender com a cultura popular, pertencentes a todas as camadas da população. Da mesma forma que não há critérios para se entrar no grupo, as pessoas podem deixá-lo quando lhes convier. As danças praticadas pelo grupo são o Jongo (Espírito Santo e São Paulo), o Cacuriá e o Baralho (Maranhão), o Coco e a Ciranda (Pernambuco), o Congo (Minas Gerais) entre outras. O propósito é efetuar criações a partir destas danças, utilizado-as como canal de expressividade e difusão desse repertório artístico.

No momento da pesquisa a configuração do Baiadô era de 18 integrantes, quinze do sexo feminino e três do masculino. A idade média do grupo era de 32 anos, variando entre vinte e cinqüenta e sete anos e tinha como membros estudantes 
universitários, profissionais liberais, diaristas, educadores e pessoas que exercem as mais variadas funções no mercado de trabalho. A atuação dos membros no grupo incluía tocar, cantar e dançar.

\section{Procedimentos}

A investigação foi feita como um pré-teste, na forma de pesquisa qualitativa e com caráter exploratório, norteador da investigação a respeito de possíveis efeitos terapêuticos encontrados vindos da participação dos integrantes no Baiadô.

Este tipo de estudo é indicado quando se possui pouco conhecimento sobre o problema abordado (Rampazzo, 2002). Considerada basicamente descritiva, a investigação qualitativa privilegia técnicas que auxiliam a descoberta de fenômenos latentes. Para tanto, foi utilizado um questionário semi-estruturado contendo perguntas que abrangessem as percepções dos integrantes do Baiadô referentes a quatro grupos de idéias: 1) como os integrantes do Baiadô conceituavam cultura popular e o campo com o qual o trabalho do grupo se predispõe a interagir; 2) a relação com a coletividade veiculada pelos integrantes e a vinculação dos mesmos no Baiadô; 3) a referência valorativa que o grupo Baiadô tinha para seus membros; 4) um mapeamento dos integrantes do grupo.

A aplicação do questionário aconteceu em março de 2008, no local de ensaio do grupo, onde seria possível a participação do maior número de integrantes. Por se tratar de um grupo aberto, os questionários validados foram selecionados segundo o critério de tempo de participação no grupo (integrantes que estivessem freqüentando o grupo por seis ou mais semanas antes da aplicação do questionário)

As respostas abertas do instrumento foram analisadas pelo método de análise de conteúdo ${ }^{8}$, uma vez que, por não se tratar de um instrumento rígido, a análise das comunicações tem uma ampla possibilidade de atuação e adaptabilidade. Esta metodologia tem duas características importantes: enriquece a tentativa exploratória, aumenta a propensão à descoberta, e permite que as hipóteses, sob a forma de afirmações provisórias, possam ser aprofundadas futuramente para verificação confirmatória (Bardin, 1977).

As respostas descritivas foram agrupadas em classificações por categorizações ${ }^{9}$, que por sua vez, foram divididas em categorias globais (feitas a partir de um critério de agrupamento que permite representar a informação de maneira condensada), e em categorias iniciais (todos os termos e argumentos colocados pelos integrantes do grupo em resposta às questões).

8 Análise de Conteúdo aparece como um "conjunto de técnicas de análise das comunicações, visando obter, por procedimentos sistemáticos e objetivos de descrição do conteúdo das mensagens indicadores (quantitativos ou não) que permitam a inferência de conhecimentos relativos às condições de produção/recepção (variáveis inferidas) destas mensagens" (Bardin, 1977, p. 42).

9 As categorias são rubricas ou classes que reúnem um grupo de elementos sob um título genérico, em relação aos caracteres comuns destes elementos (Bardin, 1977, p.117).

\section{Resultados}

Os resultados apontados exemplificam as categorias globais apontadas pelas respostas dos participantes da pesquisa. Alguns dos argumentos apontados como categorias iniciais serão reproduzidas no corpo do texto para uma melhor compreensão dos resultados apontados.

Em relação ao conceito de cultura popular, 53\% das respostas dos participantes a relacionam com aspectos sócio-históricos; 21\% de respostas apontam aspectos ligados ao fenômeno artístico; quinze por cento acreditam que cultura popular seja um conceito que envolva aspectos educacionais e de transmissão de conhecimento; já oito por cento das respostas dadas apontam aspectos emocionais como parte deste conceito.

Oitenta e três por cento de respostas dos integrantes do grupo apontaram um conhecimento prévio a respeito de elementos de cultura popular antes da entrada no grupo. Estes elementos se faziam presentes eram: cirandas na escola, festa de folia de reis, pais festeiros em festas populares, leituras e músicas compartilhadas com familiares na infância, entre outros.

Como aspectos motivadores à entrada no grupo Baiadô, $17 \%$ dos termos e argumentos fornecidos indicaram o aparato artístico como propiciador de desejo para a entrada no grupo (fitas do vestuário, cores das roupas, sonoridade dos instrumentos). Trinta e quatro por cento de respostas reconheceram a entrada no Baiadô motivada por necessidades e interesses pessoais/emocionais; já a interação intergrupal vista nas apresentações foi a motivadora de entrada no Baiadô em dez por cento dos argumentos; e $20 \%$ apontam aspectos particulares ao grupo (alegria, criatividade, energia, convívio com diferenças, entre outros) como o agente motivador para o pertencimento; quinze por cento dos termos fornecidos pelos participantes disseram ter sido interesses profissionais os favorecedores à entrada no mesmo; e cinco por cento atribui a chegada ao Baiadô influenciados por vias externas (amigos).

A forma de atuação pessoal no grupo entendida pelos integrantes estão nas seguintes categorias: $32 \%$ das respostas apontam a visão dos participantes como possuidores de um papel artístico no grupo (dançam, tocam, pensam no grupo cenicamente); 16\% se colocaram como "pertencentes ao grupo" (fazer volume); a mesma porcentagem de respostas aponta para integrantes que não sabem o seu papel dentro do grupo e, na mesma proporção, as respostas dos baiadores indicam uma atuação relacionada a um interesse pessoal no grupo (aprendiz, pesquisador, profissional buscando conhecimento prático e teórico). Outra referência encontrada, também com $16 \%$ de respostas, foi a existência de respostas dos integrantes direcionadas para um papel atuante no grupo (por exemplo: colaboradora e auxiliar nas apresentações e cursos).

Como modificações percebidas pelos baiadores após a entrada no grupo, pode-se apontar em 49\% das respostas a identificação dos membros reconhecendo-se com modificações internas, como por exemplo: estar mais desperto, perda da timidez, melhor posicionamento perante os outros, sentir-se com mais atividade e mais feliz, senti-se importante como pessoa, fortalecimento de autoconfiança; $24 \%$ das respostas apontam a existência de uma ampliação de conhecimento 
decorrente da participação no Baiadô (interesse pelas diferenças populares, conhecimento de outras realidades, ampliou a visão de mundo, melhorou a performance como atriz, entre outros); $16 \%$ apontaram como ganhos modificações na relação com as pessoas (trabalhar melhor em grupo, mais abertura com os outros, trabalhar preconceitos, respeitar diferenças); seis por cento dos integrantes apontaram modificação quanto ao aspecto artístico (melhora no trabalho de criação, melhora na afinação e nos conhecimentos musicais); dois por cento dos integrantes não perceberam mudança alguma após a entrada no grupo.

Os integrantes do Baiadô atribuem valor ao grupo da seguinte maneira: $94 \%$ dos integrantes o colocam como importante pela possibilidade de aquisição de cultura; já $56 \%$ das pessoas estudadas entendem que o grupo é importante pela possibilidade de obtenção de informações, como lazer, e reconhecem nele um valor educacional. Somente 39\% das pessoas entendem o Baiadô com um valor terapêutico.

Uma vez que a questão do efeito terapêutico do grupo em seus participantes foi o motivador desta investigação, foi adicionada ao questionário, uma pergunta a respeito das razões pelas quais o Baiadô tinha valor terapêutico para seus integrantes. Primeiramente a pergunta foi feita com 39\% dos sujeitos (somente com os que reconheceram a valoração terapêutica como algo identificado no grupo Baiadô). Em porcentagens iguais, $32 \%$ de respostas, os participantes apontavam como características terapêuticas identificadas do Baiadô, o relacionamento no grupo (integração, trabalho com diferenças, descontração em grupo, contato com o outro, momentos de alegria, entre outros), e a percepção de modificações internas (sensação de produção, melhora da auto-estima, sentir-se bem, treinamento de senso de humor, resgate de alegria, sensualidade e segurança); $18 \%$ de respostas indicavam a função terapêutica vinda das possibilidades encontradas dentro do grupo (esquecer temporariamente problemas, poder soltar-se, ser valorizado pelo que é, liberdade de expressão); a música também foi apontada como um fator terapêutico em seis por cento das respostas; e o trabalho com o corpo (dança) esteve presente em $15 \%$ dos argumentos apontados pelos baiadores.

Em decorrência da riqueza dos dados encontrados, foi adicionado à investigação as respostas sobre valor terapêutico apontadas no grupo Baiadô por seus integrantes ${ }^{10}$. Os resultados a partir dos argumentos coletados, em 100\% dos participantes da pesquisa, foram os seguintes: $41 \%$ das respostas reconheciam haver uma característica terapêutica no grupo pela relação grupal (envolvimento no grupo, encontrar pessoas, convivência, funcionava como algo terapêutico para quem interage nas apresentações).

Trinta e cinco por cento das respostas apontaram um valor terapêutico em decorrência da relação com as artes (para os participantes, as artes trabalham movimento e a saúde corporal, o psicológico, características da personalidade, a criatividade e a dança faz a pessoa se sentir melhor). Já 19\% das respostas apontam o reconhecimento de uma relação

10 Questão de número 20: "mesmo que não tenha assinalado a opção "d" da pergunta número quinze, a nossa pesquisa tem o interesse em levantar as possibilidades de um eventual valor terapêutico do Grupo Baiadô. O que você acha dessa investigação? Especifique. terapêutica pelos efeitos pessoais percebidos nos integrantes (diversão, aumento de auto-estima, autoconhecimento, disposição e alegria); somente em cinco por cento de respostas o valor terapêutico do Baiadô não foi reconhecido.

\section{Discussão}

Dentro da proposta de estudo deste trabalho, interessa verificar a percepção dos membros do Baiadô sobre sua relação com o grupo, a fim de identificar possibilidades de efeitos terapêuticos ocorridos após a entrada no mesmo. Um dos primeiros pontos observados na realização deste trabalho foi a carência de pesquisas que envolvem a relação entre elementos da cultura brasileira (em especial sua dança) com aspectos terapêuticos, principalmente em sendo o Brasil um país com tamanha diversidade e riqueza cultural. Apesar de o grupo Baiadô ter como referência o trabalho com expressões e elementos estéticos da cultura popular fazendo mediações entre esses dois universos, ele não é um grupo tipicamente tradicional.

Em relação às respostas fornecidas pelos baiadores sobre cultura popular, percebe-se que a compreensão deste conceito está relacionada à vivência dos mesmos com o grupo. Um alto número de respostas, $53 \%$, indica características como as tradições, costumes, línguas, identidades (local e nacional), ou crenças de um povo como característico desta cultura, indo de encontro a visão dos autores a respeito deste tema. Questões como o "dinamismo" da cultura popular e de sua característica de reelaboração podem ser encontradas em Catenacci (2001), Xidieh (1967 conforme citado por Bosi, 1986), e Meira (2007).

Algumas respostas que indicam como cultura popular a "alegria", "força", "energia" podem ser apontadas como características observadas pelos baiadores no próprio grupo. A grande maioria dos integrantes do Baiadô já conhecia aspectos da cultura popular antes mesmo de ingressar no grupo. Esse fato indica haver uma familiaridade com a cultura popular e, talvez isto esteja influenciando alguns membros do grupo no interesse despertado em agregarem-se ao Baiadô.

Apesar de se tratar de um grupo que tem nas danças brasileiras o ponto forte de suas apresentações públicas, a interação coletiva nas performances teve somente dez por cento de respostas indicativas como motivadoras para o ingresso no Baiadô. A maioria das respostas (34\%) mostrou como sendo necessidades e interesses pessoais os propulsores para que estes freqüentassem aos ensaios.

Dentre as modificações ocorridas nos baiadores após a entrada no grupo, tem-se, em $16 \%$ das respostas, o registro de envolvimento com relacionamentos interpessoais, tais como: uma melhora no trabalho com grupos, e com um convívio igualitário e desprovido de preconceitos com os demais integrantes e pessoas fora do grupo. Também foram apontadas melhoras quanto à receptividade e quanto à entrega no relacionamento com outros indivíduos.

$\mathrm{O}$ fator de relação coletiva foi muito mencionado pelos integrantes do grupo em todo o quadro de respostas apresentadas. Uma necessidade de sociabilização pressupõe a existência de uma carência de sociabilidade, seja em um ambiente que propicie uma autenticidade de expressão pes- 
soal, seja com o intuito de amar ou de encantar, encontrado nas respostas. Apesar de alguns integrantes terem visto o Baiadô como um grupo de dança, eles o identificam como capaz de suprir necessidades emocionais e não só artísticas. $\mathrm{O}$ aparato artístico do Baiadô foi apontado por somente 17\% das respostas como impulsionador para a participação no grupo.

Por se tratar de um grupo onde a dança, a música e o canto acontecem de forma simultânea, é interessante notar o fato de não ter havido indicação em relação ao ato de cantar nas respostas dos baiadores. Nem todos os participantes sentem-se com a obrigação do canto no grupo, mesmo que cantar seja uma de suas funções.

Características intrínsecas ao Baiadô, como por exemplo, a disponibilidade para entradas de novos membros é um forte estímulo ao crescimento pessoal para seus participantes. Desta forma, os efeitos advindos desta "vivência diversificada", seja entre seus participantes ou por meio do convívio com grupos de cultura popular, são compreendidos pelos baiadores como propiciadores de mudanças em suas vidas. Todavia, e de forma curiosa, o interesse despertado para um aprofundamento a respeito da cultura popular teve somente seis por cento de argumentos mesmo em se tratando de um grupo que dialoga com esta cultura o tempo todo.

Não foi solicitado aos participantes da pesquisa que definissem o termo terapêutico e nenhum dos demais termos oferecidos para a escolha valorativa apontassem no grupo. Também não foi fornecida uma definição à priori destes conceitos a fim de que os integrantes pudessem basear suas respostas na própria experiência. Desta forma, $94 \%$ dos baiadores percebem o grupo e com o valor de aquisição de cultura, 56\% como obtenção de informação; $56 \%$ como lazer; $56 \%$ com valor educacional; e somente $39 \%$ do grupo o vê com valor terapêutico. Nesta análise, o convívio em grupo tem uma grande influência nos participantes do Baiadô, seja por meio de sua integração, do contato com as diferenças ou da alegria que as relações estabelecidas proporcionam para eles. A dinâmica grupal desenvolve condições para que se possa lidar com aspectos de diferenças pessoais.

Dos integrantes que reconheceram o Baiadô com valor terapêutico, alguns aspectos merecem ser revistos. Para esta parcela do grupo, este teria um valor terapêutico por: proporcionar descontração; trabalhar e exercitar o convívio com diferenças e, conseqüentemente, propiciar a comparação de estilos de vida; favorecer o contato com outras pessoas; permitir aprendizados e treinos de senso de humor, além de ter exercido um papel de resgate na alegria, sensualidade, segurança. O grupo ajuda também na valorização pessoal, no esquecimento de problemas e na liberdade de expressão de seus participantes. A relação com as possibilidades criativas e de improvisação, apesar de mencionadas, teve uma baixa freqüência de argumentos.

Mesmo fornecidas por menos da metade do grupo (39\%), as respostas acima são importantes diretrizes no pensamento a respeito de qual o papel a música e a dança brasileira tiveram na visão de valoração terapêutica por parte destes participantes.

De acordo com a resposta ao questionamento sobre o valor terapêutico em seus integrantes, respondida por todos os participantes da pesquisa, percebe-se que as relações sociais, a convivência, a troca de experiências entre seus membros e entre a cultura popular foram também identificados como existentes e reconhecidos como terapêuticos. Características tais como o aumento da disposição, da tolerância, do autoconhecimento, sentir-se bem, e estar mais alegre, também foram argumentos apontados.

Retomando o conceito de psicoterapia colocado por Wolberg (1988) uma das formas de se considerá-la é como uma abordagem que tenta influenciar ou assistir a um paciente a uma melhor maneira de pensar, de sentir e de se comportar. Em relação a este conceito, pode-se afirmar que a permanência dos integrantes atuais no Baiadô lhes proporcionou ganhos terapêuticos, uma vez que os mesmos reconheceram ter havido modificações envolvendo aspectos internos, de ampliação de conhecimento, e de relação com as pessoas. Estas modificações indicam aquisições pessoais, identificadas pelos membros do grupo, tais como: aumento da alegria de viver, ser mais feliz, melhora da timidez, um fortalecimento da autoconfiança, maior consciência corporal e de potencialidades, melhor participação no ambiente e de formas de conversar.

Mesmo fora de um ambiente com propriedades psicoterapêuticas, o trabalho coletivo é propiciador de ganhos nesta área. Chace (conforme citado por Abreu e Silva, 1977) aponta que a realização de um trabalho em grupo traz benefícios terapêuticos, pois uma atividade grupal por meio da dança auxilia o indivíduo a se sentir próximo de outras pessoas.

É certo que o contexto grupal mencionado nesta investigação utiliza-se das artes para manter-se, pois o foco do grupo são as danças brasileiras. Todavia, é também curioso o fato de que, uma melhoria no aspecto artístico dos integrantes do Baiadô foi muito pouco apontada, com somente seis por cento de respostas. Assim, os dados sugerem que, mesmo sendo um grupo que dança, canta e toca, é a relação grupal, na forma como se apresenta hoje, o grande propiciador de efeitos terapêuticos percebidos pelos integrantes, e não a situação artística isoladamente. A arte da dança ocupa um lugar modesto na busca de identificação da presença de um valor terapêutico dentro do grupo em questão.

É importante salientar que todas as respostas obtidas nesta investigação se deram por meio de um instrumento específico. Este estudo, apesar de possibilitar a realização de várias considerações, possui também, limitações (Amaro, Póvoa \& Macedo 2005). A relatividade do instrumento e do contexto de toda esta investigação são fatores dignos de serem considerados. Eventos como: a realização do estudo ter sido feita em um grupo aberto e fluido; tratar-se de um número relativamente pequeno de investigados (dezoito); da aplicação do questionário ter sido realizada no local de ensaio e ter ocupado momentos destinados ao mesmo, são variáveis importantes para serem atentadas.

A dança criada a partir de comunidades faz parte da história da humanidade desde os povos primitivos (Sachs, 1937). Aliado ao desenvolvimento das cidades, na medida em que esta arte foi se categorizando em danças folclóricas e espetaculares (Abreu e Silva, 1977), verifica-se um distanciamento entre as duas. A forma espetacular vai se afastando das origens expressivas das danças populares, ficando, então, 
formatada a uma estética e padronização de estilos e ligada a padrões socialmente aceitos.

A relação com o chão, com o elemento terra, tem um vínculo altamente observável em grupos ligado à cultura popular. Esse enraizamento ou a vivência deste "aterramento" podem ser importantes para nortear possibilidades terapêuticas. Nos grupos populares, essa relação de vínculo acontece a partir das danças e de sua relação com o solo. É possível fazer uma analogia com o grounding que Lowen (2007) descreve em seu trabalho. Para Lowen (2007), estar em suspensão implica em uma impossibilidade de se mover na direção da realização das metas da vida. Da mesma forma, no enraizamento comentado por Rodrigues (1997), são os pés que assumem a condução e traçam caminhos para serem percorridos integralmente pelo corpo.

A partir dos movimentos e da relação com o solo, característicos das danças brasileiras, contribuições podem ser desenvolvidas para que a busca de grounding, ou enraizamento, aconteça de forma lúdica ou brincada, em situações terapêuticas.

O fato de o valor terapêutico do grupo ter sido o menos reconhecido como existente, por seus participantes pode ser explicado por ser o Baiadô um grupo de diversidades. Para muitos de seus participantes, o campo das psicoterapias está fora do universo de referência pessoal. Um ponto a ser considerado é que, independentemente do nível de formação educacional, social, econômico ou de interesses particulares, os participantes reconheceram em si melhoras a partir de sua freqüência no grupo, e é desnecessária, para eles, a identificação destes ganhos como terapêuticos.

Alguns apontamentos podem ser indicados em decorrência das respostas fornecidas pelos integrantes do Baiadô: 1) obtêm-se ganhos terapêuticos em situações fora das legitimamente tidas como terapêuticas; 2) um terapeuta ou um facilitador de trabalhos com danças brasileiras, precisa estar disponível à criação de uma ambiência de alegria, criatividade, improvisação e com relacionamentos em grupo; 3 ) o papel terapêutico que o Baiadô tem para alguns de seus integrantes não vem necessariamente da sua ligação com a dança, mas do relacionamento que os baiadores estabeleceram entre si. É certo que estas relações podem estar atreladas à própria dinâmica artística do grupo, mesmo que, terapeuticamente, estas características não tenham sido apontadas como terapêuticas por seus participantes; 4) existem elementos da cultura brasileira que possibilitam melhoras terapêuticas para quem delas participa, sem que estes estejam buscando um trabalho psicológico; 5) a cultura popular possui e cria elementos que são positivos, capazes de auxiliarem terapeuticamente os seus participantes; 6) dentro de um trabalho em grupo, os valores e conceitos vividos no mesmo costumam ter uma função de referencial para seus integrantes; 7) uma vez que a entrada no grupo Baiadô teve a maior freqüência de respostas com relação a um suprimento de necessidades afetivo/emocionais de seus membros, em um trabalho terapêutico, é importante que a atenção na relação grupal seja compreendida pelo terapeuta.

Uma vez que a situação terapêutica necessita oferecer um contexto de segurança para os seus pacientes, em um ambiente grupal onde se utiliza a dança com esta finalidade, a idéia de definição de papéis e valorização dos participantes pode ser um fator engajador destes integrantes na atividade.

Indicadores de aprofundamento para estudos futuros sugerem que, um trabalho terapêutico auxiliado pelas danças brasileiras, pode ser mais efetivo se for desenvolvido com pessoas que já tenham tido um conhecimento prévio a respeito de grupos de cultura popular, mesmo que estas pessoas não estejam, diretamente, vinculadas a estes grupos. Segundo Duarte Jr. (1995, p. 60), "novos significados e simbolizações somente são aprendidos na medida em que se conectem a experiências de vida".

A dança é reconhecida como uma arte de execução, caracterizada pela habilidade de se utilizar o movimento de forma simbólica, gerando, assim, significados, e desenvolvendo a capacidade intelectual do homem (Freire, 2001). Uma vez que esta arte é um potente veículo de transformação e expressão da criatividade humana, pois o trabalho corporal engloba muito das funções do organismo humano (Pregnolatto, 2004), a dança auxilia a expressão em movimentos, seja por uma comunicação estabelecida entre o ser humano e o seu meio, quanto em relação à cultura e sociedade a que pertence (Fortin, 1999).

Concernente a um trabalho corporal, a relação do movimento é compreendida como reveladora de informações a respeito de emoções internas e de processos mentais. Este pode não ser o intuito da utilização de danças brasileiras como instrumento terapêutico. Porém, aspectos como: a utilização da voz e o próprio ato de se dançar músicas folclóricas, encontrados nos trabalhos de Maria Fux; o sistema de "encontro aberto" vivenciado nos trabalhos Rolando Toro (Crema, 1983) e a crença no potencial do grupo e do estabelecimento de relações humanas significativas como ativadores de processos terapêuticos, apontados por Chace (conforme citado por Abreu e Silva, 1977), têm características semelhantes às encontradas no mundo das culturas populares.

Incontáveis são as razões que conduzem a uma decisão pessoal, em prol da busca de processos terapêuticos. Algumas destas possuem origens dolorosas, outras são mais limitadoras, e todas ensejam cuidado, carinho e respeito por parte do terapeuta. A relevância de situações acontecidas nos grupos de comunidades e de celebrações populares com seus vínculos, cantigas e danças, pode funcionar como valiosos resgates de alegria, de entusiasmo, de auto-valorização e de expressão de criatividade, por meio da arte e do movimento.

A voz do povo diz que "quem canta, seus males espanta". Se somente cantar tem este efeito, o que espantaria, então, quem não só canta, mas também dança? $\mathrm{Na}$ cultura popular, os produtos construídos passam pelos sentidos e pela emoção de seus integrantes, dando à vida um significado coletivo e pessoal, reconhecido como conquista ancestral e transferido aos seus descendentes na continuidade de sua história. A utilização da dança, e de outros elementos desta cultura, apresenta um rico campo de (respeitosa) investigação por parte dos profissionais da academia, no caso aqui presente, da Psicologia, ao agregar conhecimentos para que estes possam ampliar a sua formação acadêmica e ousarem na busca da saúde de seus pacientes. 


\section{Referências}

Abreu e Silva, N. N. (1977). A Dança: uma arte a serviço da terapia Dissertação de Mestrado, Universidade de São Paulo, São Paulo.

Amaro, A., Póvoa, A., \& Macedo, L. (2005) A arte de fazer questionários. Faculdade de Ciências da Universidade do Porto, Departamento de Química, Metodologias de Investigação em Educação. Acessado de http://www.jcpaiva.net/getfile. php?cwd=ensino/cadeiras/metodol/20042005/894dc/ f94cl\& $f=a 9308$

Bardin, L. (1977). Análise de Conteúdo. Lisboa: Edições 70.

Bosi, E. (1986). Cultura de Massa e Cultura Popular: Leitura de Operárias ( $6^{\mathrm{a}}$ ed.). Petropolis: Vozes.

Bramble, D. M., \& Lieberman D. E. (2004). Endurance running and the evolution of Homo. Nature, 432(7015), 345-52.

Castro, E. D. (1992). A Apropriação de si mesmo através da dança. Dissertação de Mestrado, Universidade de São Paulo, São Paulo.

Catenacci, V. (2001). Cultura Popular: Entre a Tradição e a Transformação. Perspectivas, 15(2), 2001. Acessado de http://www. scielo.br/scielo.php? script $=$ sci_arttext\&pid =S0102-88392001000200005 \&lng=en\&nrm=isso.

Crema, R. (1983). Psicodança e Análise Transacional: Uma proposta de Integração ( $3^{\mathrm{a}}$ Ed.). Brasília: H. P. Mendes.

Duarte Jr., J. F. (1995). Fundamentos Estéticos da Educação (4 ed.) Campinas: Papirus.

Farr, M. (1997). The Role of Dance/Movement Therapy in Treating At-Risk African American Adolescents. The Arts in Psychoterapy, 24(2), 183-191.

Fortin, S. (1999). Educação Somática: Novo Ingrediente da Formação Prática em Dança (tradução Márcia Strazzacappa). Cadernos GIPE - CIT, no 2. Estudos do Corpo. Salvador: UFBA.

Freire, I. (2001). Dança-Educação: O Corpo e o Movimento no Espaço do Conhecimento. Caderno Sedes, 21(53), 31-55.

Fux, M. (1983). Dança experiência de Vida. $4^{\text {a }}$ Ed. São Paulo: Summus.

Kock, S., Morlinghaus, K., \& Fuchs, T. (2007). The Joy Dance Specific Effects of a Single Dance Intervention on Psychiatric Patients with Depression. The Arts in Psychotherapy, 34, $340-349$.
Langer, S. (2006). Sentimento e Forma. São Paulo: Perspectiva. Lowen, A. (2007). Uma Vida Para o Corpo: Autobiografia de Alexander Lowen. São Paulo: Summus.

Lowen, A. \& Lowen, L. ( 1985). Exercícios de Bionergética: o caminho para uma saúde vibrante. São Paulo: Ágora.

Meira, R. B. (2007). Processo de Criação Popular e a Dança Brasileira. Circuladança Minas, Uberlândia.

Peto, A. C. (2000). Terapia Através da Dança com Laringectomizados: Relato de Experiência. Revista Latino-Am.de Enfermagem,. 8(6), 35-39.

Pregnolatto, D. (2004). Criandança - uma visita à metodologia de Rudolf Laban. Brasília, DF: LG. Secretaria do Estado da Cultura do DF.

Rampazzo, L. (2002). Metodologia Cientifica. Ed. Loyola: São Paulo.

Rodrigues, G. (1997). Bailarino-Pesquisador-Intérprete: Processo de Formação. Rio de Janeiro: Fundação Nacional de Arte FUNARTE.

Sachs, C. (1937). World History of Dance. New York: W.W. Norton \& Company Inc.

Thulin, K. (1997). When Words Are Not Enough: dance therapy as a method of treatment for patients with psychosomatic disorders. American Journal of Dance Therapy, 19(1), 25-43.

Zanella, A. V., \& Titon, A. P. (2005). Análise da produção científica sobre criatividade em programas brasileiros de pós-graduação em psicologia (1994-2001). Psicol. estud., 10(2)l. Acessado de http://www.scielo.br/scielo.php? script $=$ sci_arttext\&pid $=S$ $141373722005000200018 \& \operatorname{lng}=$ pt\&nrm $=$ iso.

Wolberg, L. (1988). The Technique of Psychotherapy. Philadelphia: Grune \& Stratton (publicado Originalmente em 1954).

Recebido em 13.02.2009

Primeira decisão editorial em 23.09.2009

Versão final em 13.02.2009

Aceito em 23.09.2009 